\title{
The Role of Mcl-1 in S. aureus-Induced Cytoprotection of Infected Macrophages
}

\author{
Joanna Koziel, ${ }^{1}$ Katarzyna Kmiecik, ${ }^{1}$ Daniela Chmiest, ${ }^{1}$ Katarzyna Maresz, \\ Danuta Mizgalska, ${ }^{1}$ Agnieszka Maciag-Gudowska, ${ }^{1}$ Piotr Mydel, ${ }^{2}$ and Jan Potempa ${ }^{1,3}$ \\ ${ }^{1}$ Department of Microbiology, Faculty of Biochemistry, Biophysics and Biotechnology, Jagiellonian University, Ul. Gronostajowa 7 , \\ 30-387 Kraków, Poland \\ ${ }^{2}$ Broegelmann Research Laboratory, The Gade Institute, University of Bergen, 50021 Bergen, Norway \\ ${ }^{3}$ Oral Health and Systemic Diseases Research Group, School of Dentistry, University of Louisville, Louisville, KY 40204, USA
}

Correspondence should be addressed to Joanna Koziel; joanna.koziel@uj.edu.pl

Received 11 October 2012; Revised 7 December 2012; Accepted 10 December 2012

Academic Editor: Chiou-Feng Lin

Copyright (c) 2013 Joanna Koziel et al. This is an open access article distributed under the Creative Commons Attribution License, which permits unrestricted use, distribution, and reproduction in any medium, provided the original work is properly cited.

\begin{abstract}
As a facultative intracellular pathogen, Staphylococcus aureus invades macrophages and then promotes the cytoprotection of infected cells thus stabilizing safe niche for silent persistence. This process occurs through the upregulation of crucial antiapoptotic genes, in particular, myeloid cell leukemia-1 (MCL-1). Here, we investigated the underlying mechanism and signal transduction pathways leading to increased $M C L-1$ expression in infected macrophages. Live $S$. aureus not only stimulated de novo synthesis of Mcl-1, but also prolonged the stability of this antiapoptotic protein. Consistent with this, we proved a crucial role of Mcl-1 in S. aureus-induced cytoprotection, since silencing of MCL1 by siRNA profoundly reversed the cytoprotection of infected cells leading to apoptosis. Increased MCL1 expression in infected cells was associated with enhanced $\mathrm{NF} \kappa \mathrm{B}$ activation and subsequent IL-6 secretion, since the inhibition of both NF $\mathcal{B}$ B and IL- 6 signalling pathways abrogated Mcl-1 induction and cytoprotection. Finally, we confirmed our observation in vivo in murine model of septic arthritis showing the association between the severity of arthritis and Mcl-1 expression. Therefore, we propose that $S$. aureus is hijacking the Mcl-1-dependent inhibition of apoptosis to prevent the elimination of infected host cells, thus allowing the intracellular persistence of the pathogen, its dissemination by infected macrophages, and the progression of staphylococci diseases.
\end{abstract}

\section{Introduction}

Staphylococcus aureus is a major cause of communityacquired and nosocomial infections, including localised and systemic life-threatening conditions, such as osteomyelitis, endocarditis, pneumonia, and septicaemia [1]. Despite the increasing morbidity and mortality due to staphylococcal infections, relatively little is known about the molecular mechanisms by which this pathogen disseminates systemically. Recent studies have shown that $S$. aureus not only survives phagocytosis by neutrophils and macrophages but is also able to persist inside these cells $[2,3]$. As is the case for Listeria monocytogenes and Mycobacterium tuberculosis [4-6], long-term survival, especially inside macrophages, may be a mechanism of dissemination of staphylococci.
This hypothesis is further supported by the observation that intracellular $S$. aureus manipulates macrophage cell signalling processes and transcription to promote survival of infected phagocytes without bacterial eradication [7]. Therefore, precise elucidation of the mechanism of induction of cytoprotection in macrophages, a potential vehicle for pathogen spreading in the host, is of high importance.

Recently, we showed that live intracellular bacteria induce cytoprotection in human and murine macrophages, allowing the pathogen to silently persist and remain invisible to the immune system $[3,7]$. We proposed that the pathogen induces a prosurvival signalling pathway through the induction of expression of antiapoptotic factors, including myeloid cell leukemia-1 (Mcl-1), an antiapoptotic protein of the Bcl-2 family. Mcl-1 possesses BCL-2 homology (BH) domains 1-4, 
similar to other antiapoptotic BCL-2 family members (BCL2, BCL-XL, BCL-W, and A1). It inhibits cell death by sequestering proapoptotic proteins (e.g., BAX, BAK, BIM, PUMA, and BAD), thus stabilising the mitochondrial membrane and preventing release of cytochrome $c[8,9]$. MCL1 expression can be induced by survival and differentiation signals such as cytokines and growth factors produced as a result of activation of a number of well-known signal transduction pathways (e.g., MAP kinases, PI3K/Akt, JAK/STAT, and $\mathrm{NF} \kappa \mathrm{B})$ [10]. Cellular levels of $\mathrm{Mcl}-1$ are regulated also by alteration of this protein turnover rate, which is dependent on PEST sequences within the N-terminal region of $\mathrm{Mcl}-1$ and other motifs that target the protein for degradation by the proteasome [8].

In the current paper, we documented the elevated level of Mcl-1 in S. aureus-infected human primary macrophages and joints in murine model of septic arthritis, associated with infiltration of macrophages into the synovia. We showed for the first time that small inhibitory (si)RNA silencing of MCL1 in $S$. aureus-infected macrophages abrogates cytoprotection against staurosporine-induced apoptosis, confirming the role of Mcl-1 in sustaining the viability of macrophages during infection. Furthermore, we established that $S$. aureus induced Mcl-1 through signalling pathways that required $\mathrm{NF} \kappa \mathrm{B}$ and IL-6, since inhibition of these pathways partly suppressed bacterial-mediated enhancement of Mcl-1 expression and cytoprotection. Therefore, we propose a model in which expression of prosurvival genes, such as MCL1, enables virulent $S$. aureus strains to circumvent cell death, thus ensuring a safe ecological niche prior to dissemination. Regulation of human macrophage longevity by intracellular S. aureus has clinical relevance for understanding the pathogenesis of Staphylococci-caused infectious diseases.

\section{Materials and Methods}

2.1. Cell Culture. PBMCs were isolated from human blood using a Lymphocyte Separation Medium (PAA) density gradient yielding the fraction highly enriched in monocytes (90\% CD14-positive) as described previously [7]. Cells were plated at $3 \times 10^{6} /$ well in 24 -well plates (Sarstedt) in RPMI1640 (PAA) supplemented with $2 \mathrm{mM}$ L-glutamine, $50 \mu \mathrm{g} / \mathrm{mL}$ gentamicin (Sigma), and 10\% autological human serum. After $24 \mathrm{~h}$, nonadherent PBMCs were removed by washing with complete medium, and adherent cells were differentiated to hMDMs in this medium for 7 days with fresh medium changed every 2 days. Blood was obtained from the Red Cross, Krakow, Poland. The Red Cross de-identified blood materials as appropriate for human subjects confidentiality assurance. Thus, the current paper adheres to appropriate exclusions from human subjects approval. The murine macrophage cell line RAW 264.7 obtained from American Type Culture Collection was maintained in DMEM (PAA) supplemented with $5 \%$ fetal bovine serum.

2.2. Bacterial Strains, Storage, and Growth Conditions. The laboratory $S$. aureus strain Newman was kindly provided by Dr. T. Foster (Trinity College, Dublin, Ireland) and E. coli strain was from laboratory stocks. Bacteria were grown to the stationary growth phase at $37^{\circ} \mathrm{C}$ overnight under constant rotation $(180 \mathrm{rpm})$, then were collected by centrifugation $(5,000 \times \mathrm{g}, 8 \mathrm{~min})$, washed with phosphate-buffered saline, and resuspended in PBS to the desired $\mathrm{OD}_{600 \mathrm{~nm}}$. Staphylococci were opsonized by incubation at $37^{\circ} \mathrm{C}$ for $30 \mathrm{~min}$ in heat inactivated FCS, washed, and resuspended in PBS. Numbers of vital bacteria in samples used in phagocytosis assay were routinely verified by plating dilutions on agar plates and counting colonies to determine CFU per mL. Heat treatment $\left(80^{\circ} \mathrm{C}\right.$ for one hour) was used to kill bacteria.

2.3. Macrophages Infection. Macrophage infection was performed using $S$. aureus and E. coli as described previously [7]. Unspecific cell activation by phagocytosis of inert particles was determined using latex beads ( $1.1 \mu \mathrm{m}$; Sigma) as described previously [7]. Phagocytosis assays were carried out for 2 hours at $37^{\circ} \mathrm{C}$ at a multiplicity of infection (MOI) of $1: 50$ (hMDMs) or $1: 5$ (RAW 264.7), resulting in $>85 \%$ of macrophages engulfing at least one bacterium. After that time cells were rinsed 4 times with ice-cold phosphate-buffered saline. Any remaining nonphagocytosed bacteria were killed by culturing in medium containing gentamicin $(50 \mu \mathrm{g} / \mathrm{mL})$ for $24 \mathrm{~h}$. The medium was then replaced with fresh media without antibiotics, and cultures were maintained for the desired time. Cells treated identically, but without bacteria, were analyzed in all experiments as a control (mock-infected cells).

For inhibitor experiments, before inoculation with bacteria or applying control stimulus, macrophages were preincubated for $30 \mathrm{~min}$ with nontoxic doses (data not shown) of the $\mathrm{NF} \kappa \mathrm{B}$ inhibitor Bay 11-7082 $(2-40 \mu \mathrm{M})$. Where indicated, cycloheximide (a final concentration $10 \mu \mathrm{g} / \mathrm{mL}$ ) was added 30 min before infection with bacteria and present in media until cells were washed $30 \mathrm{~min}$ after infection. This treatment reduced de novo translation of proteins in macrophage by $95.5 \%$ as determined by ${ }^{35} \mathrm{~S}$-Met incorporation (data not shown).

2.4. Viability Assays. After S. aureus phagocytosis and/or treatment with compounds inducing apoptosis, macrophage viability was examined by lactate dehydrogenase (LDH) release. The LDH release assay was performed using a CytoTox96 Non-Radioactive Lactate Dehydrogenase Cytotoxicity Assay kit (Promega). Infected and control hMDMs or RAW 264.7 cells in a 24 -well tissue culture plate $\left(3 \times 10^{5}\right.$ cells per well) were treated with $1 \mu \mathrm{M}$ staurosporine (STS; Sigma) added $2 \mathrm{~h}$ or $24 \mathrm{~h}$ after-infection as a stimulator of apoptosis. Samples were then incubated for $6 \mathrm{~h}$ or $24 \mathrm{~h}$, and $200 \mu \mathrm{L}$ of culture medium were withdrawn and subjected to analysis as described previously [7].

2.5. Analysis of Caspase-3 Activity. The activity of caspase3 was determined by release of 7-amino-4-trifluoromethylcoumarin (AFC) from a DEVD-AFC peptide substrate. Cells, both control and exposed to $S$. aureus, with or without apoptotic stimuli, were collected by centrifugation $(200 \times \mathrm{g}$, $5 \mathrm{~min}, 4^{\circ} \mathrm{C}$ ), washed with ice-cold PBS, and resuspended 
in $100 \mu \mathrm{L}$ of lysis buffer $(50 \mathrm{mM}$ Tris, $\mathrm{pH} 7.5,150 \mathrm{mM}$ $\mathrm{NaCl}, 1 \%$ NP-40, 0.5\% deoxycholic acid, and 0.1\% SDS). Samples were then incubated on ice for $20 \mathrm{~min}$ and subjected to centrifugation $(16,000 \times \mathrm{g}, 10 \mathrm{~min})$. The protein content of supernatants was measured using a BCA method, and caspase activity was determined by using a Spectra Max Gemini EM (Molecular Devices) as described previously [7].

2.6. Protein Isolation and Immunoblotting. Whole cellular extracts from control and stimulated cells were prepared using $100 \mu \mathrm{L}$ of RIPA-lysis buffer $(0.25 \%$ Na-deoxycholate, 0.5\% Nonidet P-40, 0.05\% SDS, protease inhibitor cocktail, and $2.5 \mathrm{mM}$ EDTA in PBS) and stored at $-20^{\circ} \mathrm{C}$. The joints of DBA1 mice were homogenized in $300 \mu \mathrm{L}$ of RIPA-lysis buffer. Equal amounts of protein $(40 \mu \mathrm{g} /$ well) were separated using SDS-PAGE (12\% or $16 \%$ gels depending on molecular mass of proteins of interest) and electrotransferred onto nitrocellulose membranes (BioRad) in buffer composed of $25 \mathrm{mM}$ Tris, $0.2 \mathrm{M}$ glycine, and $20 \%$ methanol $(30 \mathrm{~V}$, overnight). Nonspecific binding sites were blocked with $3 \%$ BSA in TTBS buffer $(20 \mathrm{mM}$ Tris, $0.5 \mathrm{M} \mathrm{NaCl}$, and $\mathrm{pH}$ 7.5 with $0.05 \%$ Tween 20 ) for $1 \mathrm{~h}$, followed by 1-2-hour incubation with the relevant primary antibody: 100-fold diluted anti-Mcl-1 (Santa Cruz), or 3,000-fold diluted anti- $\beta$ actin (Sigma). Membranes were washed extensively in TTBS buffer and incubated with secondary horseradish peroxidase(HRP-) conjugated antibodies, 10,000-fold diluted donkey anti-rabbit IgG, or 20,000-fold diluted sheep anti-mouse IgG, for $1 \mathrm{~h}$ in TTBS buffer containing 1\% BSA. Membranes were washed $(4 \times 15 \mathrm{~min})$ in TTBS buffer, and blots were developed using ECL detection (Western Blotting Detection Reagents; Amersham Biosciences).

2.7. Densitometric Analyses. Densitometric analyses of western blots were performed using Kodak Digital Software. Results are presented as mean values of arbitrary densitometric units corrected for background intensity or as the fold of increase over a level characteristic for nonstimulated cells.

2.8. Quantitative PCR ( $q R T-P C R)$. Total cellular RNA was extracted from cultured hMDMs using aRNeasy Mini Kit (Qiagen) according to the manufacturer's instructions. RNA samples were DNase treated, and cDNA was prepared by reverse transcription using RevertAidTM First Strand cDNA Synthesis Kit (Fermentas). Five hundred nanograms of RNA from each sample were used for cDNA synthesis reaction with oligo(dT) primers according to the manufacturer's instructions. Quantitative PCR reaction was performed with an SYBR Green method in a reaction volume of $20 \mu \mathrm{L}$, containing $1 \mu \mathrm{L}$ of cDNA sample, $0.5 \mu \mathrm{M}$ of each primer, and 1x SYBR Green JumpStart Taq Ready Mix (Sigma). qRT-PCR forward and reverse primers for IL-6, MCL1, and $M C L 1 S$ genes and for the housekeeping EF-2 gene (used for normalization) are listed in Table 1 . After 5 min of initial denaturation at $95^{\circ} \mathrm{C}$, reactions were carried out for 40 cycles at the given conditions: denaturation, $95^{\circ} \mathrm{C}, 20 \mathrm{sec}$; annealing, $56^{\circ} \mathrm{C}-62^{\circ} \mathrm{C}$ (as shown in Table 1), $60 \mathrm{sec}$; extension, $72^{\circ} \mathrm{C}$,
$60 \mathrm{sec}$; followed by a final elongation step at $72^{\circ} \mathrm{C}$ for $10 \mathrm{~min}$. All the reactions were performed in duplicates. Means for threshold cycle $(\mathrm{Ct})$ values were calculated and analyzed using the "delta-delta Ct" quantification method [11]. Routinely, for the evaluation of quality of qRT-PCR reactions, samples were resolved on nondenaturing 1.5\% agarose gels and visualized by staining with ethidium bromide.

2.9. Cytokine Assay. Two hundred $\mu \mathrm{L}$ of cell culture supernatants were collected and stored at $-80^{\circ} \mathrm{C}$ until analysis. The level of IL- 6 was determined by using commercially available ELISA kits according to the manufacturer's instructions (R\&D Systems).

2.10. Transfection with siRNA. Silencing of the MCL1 gene expression was accomplished by transfection of cells with specific siRNA or with negative control siRNA (Accell Smart pool and Control pool, resp., Thermo Scientific Dharmacon). Briefly, for each of transfected wells, siRNA (final concentration $60 \mathrm{nM}$ ) was combined with $3 \mu \mathrm{L}$ of lipofectamine 2000 (Invitrogen) in Opti-MEM medium (Invitrogen). Transfection was performed for $4 \mathrm{~h}$ followed by $24 \mathrm{~h}$ of normal cell growth before desired assays were performed.

2.11. Evaluation of $N F \kappa B$ Activity. $\mathrm{NF} \kappa \mathrm{B}$ activity was measured in nuclear protein extracts by the EMSA method. Nuclear extracts were prepared by a miniextraction procedure as described before [12]. The protein concentration was measured with bicinchoninic acid (BCA method), and the obtained extracts were frozen $\left(-80^{\circ} \mathrm{C}\right)$ in $10 \%$ glycerol. For the NF- $\kappa \mathrm{B}$-directed EMSA, double-stranded probes were prepared using the pair of primers AGCTTCAGAGGGGACTTTCCGAGAGG and AGTCTCCCCTGAAAGGCTCTCCTCGA. EMSA was performed as described before [12].

\subsection{Septic Arthritis Induction and Examination of Infection.} Male DBA1 mice (8-12 weeks old) were obtained from the breeding unit of the Department of Human Developmental Biology, Jagiellonian University, School of Medicine. Mice were fed autoclaved food and water. All experiments were conducted according to guidelines of the Animal Use and Care Committee of the Jagiellonian University School of Medicine. Mice were inoculated with $S$. aureus in the tail vein $\left(5 \times 10^{7}\right.$ in $\left.200 \mu \mathrm{L}\right)$ at day 0 . The overall condition was evaluated by assessment of body weight and general appearance. The hind paws and forepaws were inspected every second day. Animals were observed daily for the presence of arthritis, and the clinical severity of disease was scored for each paw on a scale of $0-4$, with the index being the sum of the scores for all four paws. The criteria for the grading were as follows: 0: no evidence of erythema and swelling; 1: mild erythema and swelling of the wrist or the ankle; 2: moderate erythema and swelling from the wrist to the metacarpal joints or from the ankle to the metatarsal joints; 3: severe erythema and swelling of the entire paw including digits; 4: maximal erythema and swelling of the paw. The bacterial load in joints, kidney, and spleen was examined at time of sacrifice ( 8 day p.i.). The organ homogenates were 
TABLE 1: Oligonucleotide sequences used in qRT-PCR.

\begin{tabular}{lcl}
\hline Oligonucleotide & Annealing $\left({ }^{\circ} \mathrm{C}\right)$ & Sequence $^{\prime}$ \\
\hline EF-2 F & 62 & $5^{\prime}$-GACATCACCAAGGGTGTGCAG-3 $^{\prime}$ \\
EF-2 R & 62 & $5^{\prime}$-TCAGCACACTGGCATAGAGGC-3 $^{\prime}$ \\
IL-6 F & 54 & $5^{\prime}$-CATCTTTGGAAGGTTCAGGTTTGT-3 $^{\prime}$ \\
IL-6 R & 54 & $5^{\prime}$-AGCCCTGAGAAAGGAGACATGTA-3 \\
MCL1 F & 62 & $5^{\prime}$-TAAGGACAAAACGGGACTGG-3' \\
MCL1 R & 62 & $5^{\prime}$-ACCAGCTCCTACTCCAGCAA-3 \\
MCL1S F & 62 & $5^{\prime}$-GCAACCACGAGACGGCC-3' \\
MCL1S R & 62 & $5^{\prime}$-GATGCCACCTTCTAGGTCCTCTAC-3' \\
\hline
\end{tabular}

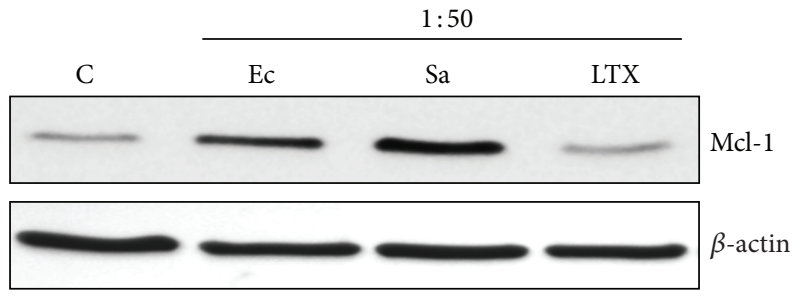

(a)

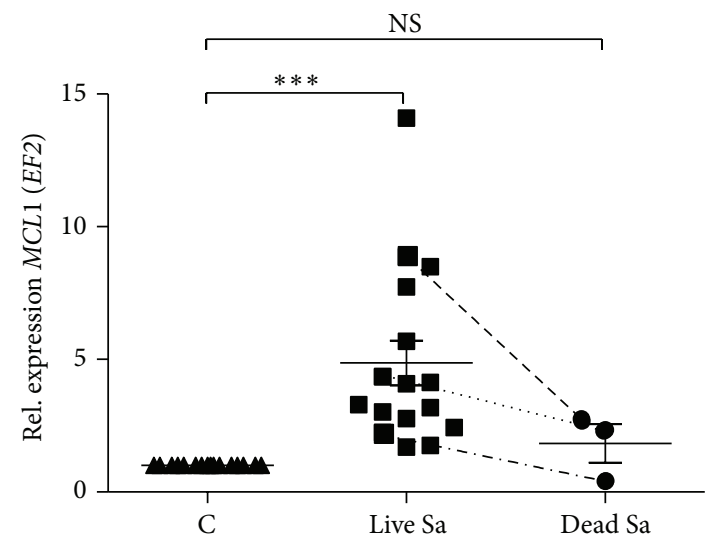

(c)

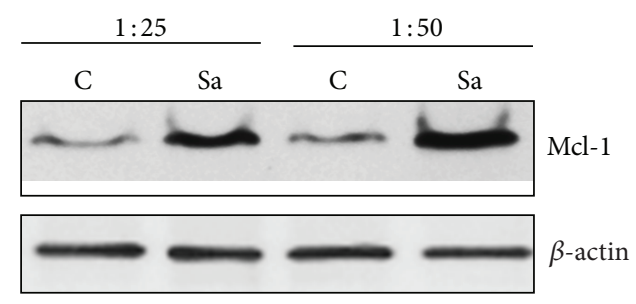

(b)

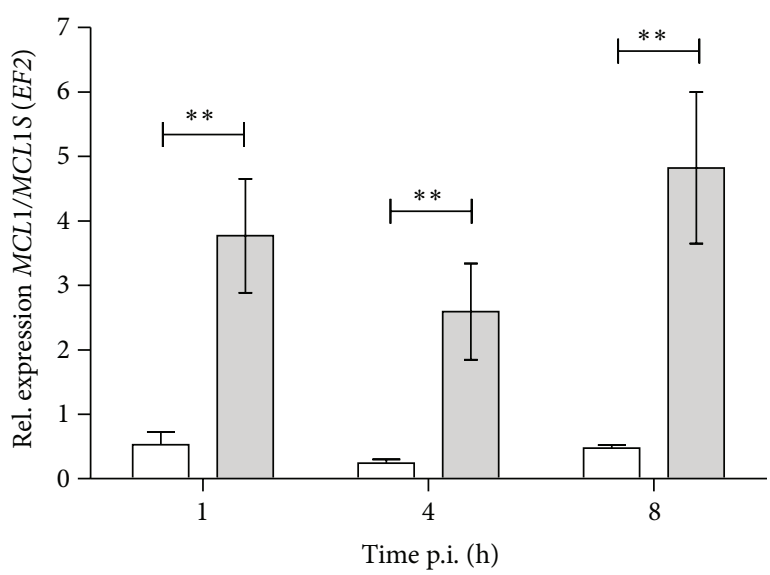

(d)

Figure 1: Mcl-1 expression is induced specifically by S. aureus phagocytosis and is dependent on bacterial dose and viability. (a) The effect of phagocytosis of S. aureus (Sa), E. coli (Ec), and latex beads (LTX) on Mcl-1 protein levels was assessed by immunoblot. After phagocytosis, cells were cultured for $8 \mathrm{~h}$ and then protein fractions were prepared as described in Section 2. Representative immunoblot from three separate experiments performed on hMDMs derived from different donors is shown. Mcl-1 was visualised by immunoblot using anti-Mcl-1-specific antibodies. (b) The effect of $S$. aureus phagocytosis on Mcl-1 levels is proportional to an infection dose. A representative immunoblot from three separate experiments performed on hMDMs derived from different donors is shown. (c) The effect of phagocytosis of live (Sa) and dead, heat-killed S. aureus (Sa HI) on MCL1 expression was determined by qRT-PCR. Data are from independent reactions using hMDMs derived from different donors. Paired points represent the response of hMDMs obtained from the same donors to both live and dead bacteria. Bars represent relative means $\pm \mathrm{SD}$. ${ }^{* * *} P<0.001$; NS: not significant. (d) The comparison of expression levels of proapoptotic MCL1S (white bars) versus antiapoptotic MCL1 (filled bars). Results were obtained by qRT-PCR from three separate experiments. ${ }^{* *} P<0.01$.

plated on tryptic soy agar and CFU counted after overnight incubation at $37^{\circ} \mathrm{C}$.

2.13. Statistics. Results were analyzed for statistical significance using the nonparametric Student's $t$-test. Differences were considered significant when $P<0.05$.

\section{Results}

3.1. S. aureus Specifically Induces Mcl-1 Expression in Human Macrophages. We previously showed that $S$. aureus can protect infected macrophages against apoptosis through upregulation of expression of antiapoptotic genes [7]. Among these genes, MCL1 plays a key role in macrophage survival 


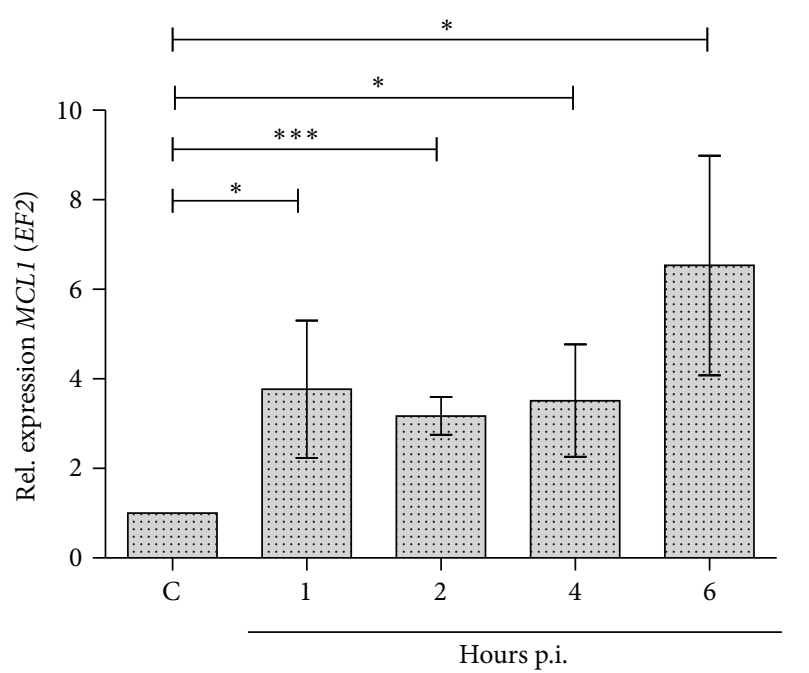

(a)

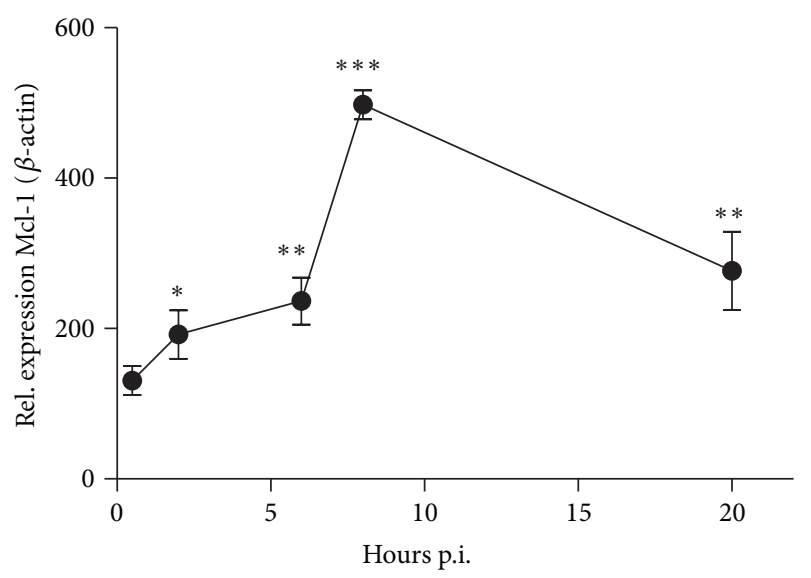

(c)

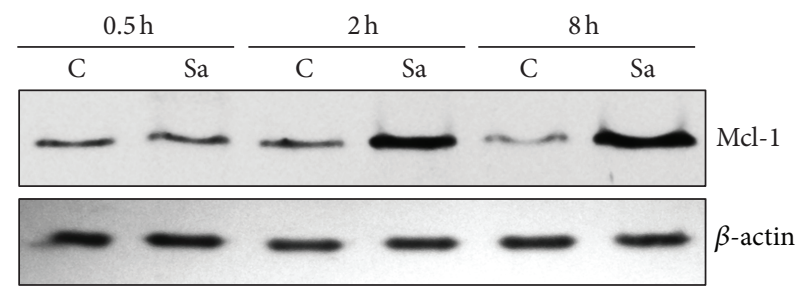

(b)

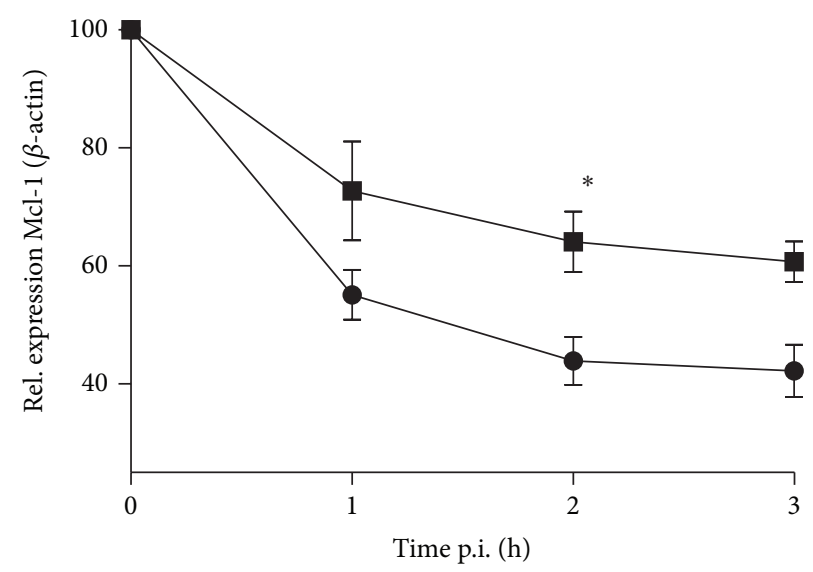

(d)

FIGURE 2: S. aureus increases both de novo Mcl-1 synthesis and stability. (a) Time course of MCL1 expression in control and S. aureus-infected macrophages (hours after-infection; p.i.) was monitored by qRT-PCR, as described in Section 2. Data represent the mean values calculated from the results of three independent experiments using hMDMs derived from different donors. Bars represent mean relative expression \pm SD. ${ }^{*} P<0.05 ;{ }^{* * *} P<0.001$. (b, c) Time course of Mcl-1 protein synthesis following S. aureus infection. Mcl-1 levels were measured at different time points between 0.5 and 20 h p.i. by immunoblot. (b) Representative immunoblot from three separate experiments performed on macrophages derived from different donors. (c) Relative Mcl-1 levels obtained by densitometric analyses of western blots. Results from three separate experiments. Data represent means $\pm \mathrm{SD} .{ }^{*} P<0.05 ;{ }^{* *} P<0.01 ;{ }^{* * *} P<0.001$. (d) Mcl-1 stability in macrophages incubated in the presence of cycloheximide (CHX) $(10 \mu \mathrm{g} / \mathrm{mL})$ in the absence (circles) or presence (squares) of $S$. aureus (MOI 1:50). At time periods of up to $3 \mathrm{~h}, \mathrm{Mcl}-1$ levels were detected by immunoblot in cell lysates. Data represents Mcl-1 levels relative to time 0 , which was arbitrarily set as $100 \%$, obtained by densitometric analyses of western blots. Data represent means \pm SD of three separate experiments. ${ }^{*} P<0.05$.

$[13,14]$. Here, we investigated potential mechanisms of Mcl1 regulation, as well as its role in cytoprotection induced by S. aureus. The Mcl-1 induction in response to phagocytosis of different bacteria and particles was examined by incubating macrophages with $S$. aureus, E. coli, or latex beads for $8 \mathrm{~h}$. $S$. aureus induced the highest level of Mcl-1, about five-times more $(4.78 \pm 0.96$-fold above the control level) than that seen in mock-infected cells (Figure 1(a)). By contrast, no change in Mcl-1 levels was observed after incubation with latex beads $(1.06 \pm 0.06)$ and only a slight upshift after E. coli $(1.78 \pm 0.63)$ (Figure 1(a)). The enhanced $\mathrm{Mcl}-1$ production in response to $S$. aureus was proportional to infection rate (Figure 1(b)) and was exerted only by viable bacterial cells (Figure 1(c)). The latter was clearly apparent from a comparison of relative levels of MCL1 mRNA induced in response to live or dead bacteria in macrophages derived from different blood donors (8.87 versus $2.75,4.36$ versus 2.35 , and 2.24 versus 0.4 , resp.). An intriguing feature of $S$. aureus-induced $\mathrm{Mcl}-1$ expression was the synthesis of an alternatively spliced MCL1 gene product (MCL1S proapoptotic isoform), which was observed at the mRNA level early after infection (Figure 1(d)). Significantly, however, the expression of MCL1S was at much lower level compared to the full-length, antiapoptotic MCL1 form (Figure 1(d)). 


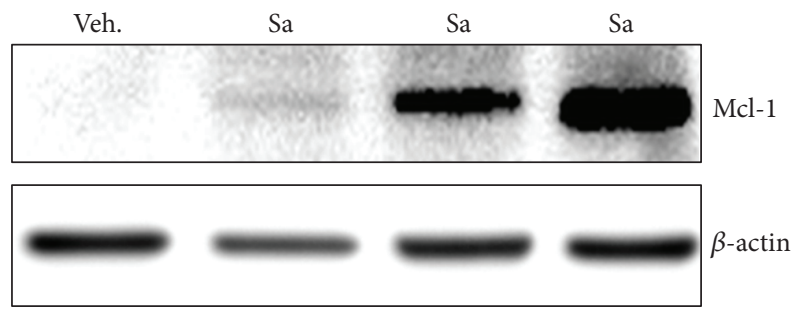

(a)

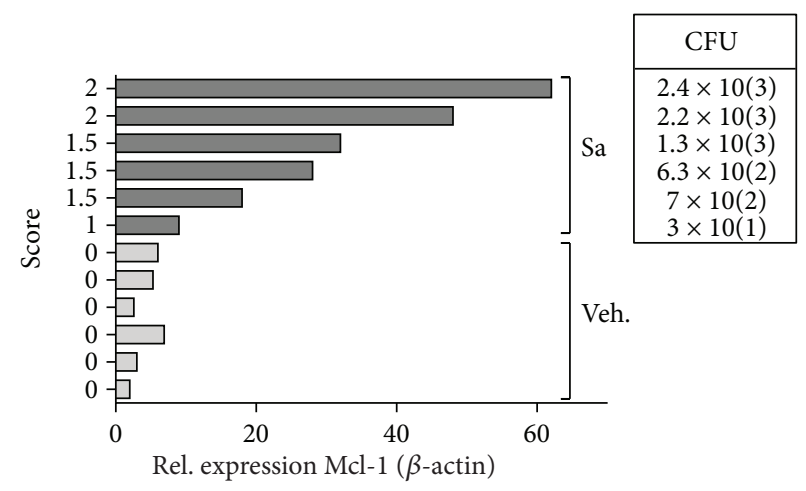

(b)

FIGURE 3: Exposure to S. aureus triggers Mcl-1 production in vivo. (a) Immunoblot reveals increase in Mcl-1 expression in inflamed joints derived from three individual S. aureus-infected mice (Sa) in comparison to noninfected animals (Veh.). A representative immunoblot from three separate experiments is shown. (b) The expression of Mcl-1 in joints correlates with infection score and bacterial load determined as described in Section 2. Data represents Mcl-1 levels in noninfected (Veh.; $n=6$ ) and S. aureus-infected (Sa; $n=6)$ animals, obtained by densitometric analyses of western blots.

Taken together, these results suggested that stimulation of Mcl-1 expression in macrophages is preferentially induced by viable $S$. aureus.

3.2. S. aureus Influences Mcl-1 Synthesis and Turnover Rate. To correlate $S$. aureus-induced cytoprotection with the expression of MCL1, we determined the time dependence of the induction of specific mRNA after macrophage challenge with bacteria. A 4-fold increase of MCL1 mRNA was observed $1 \mathrm{~h}$ after-infection, with sustained upregulation observed for up to $6 \mathrm{~h}$ (Figure 2(a)). At the protein level, Mcl-1 levels were significantly increased $2 \mathrm{~h}$ after-infection, reached a maximum at $8 \mathrm{~h}$, and remained at 3 -fold higher levels compared to mock-infected cells for at least $20 \mathrm{~h}$ (Figures 2(b) and 2(c)).

Since the observed high levels of expression of Mcl-1 in $S$. aureus-infected macrophages could be the result of either de novo synthesis or the decreased turnover rate, we compared Mcl-1 stability in macrophages treated with cycloheximide in the absence and presence of $S$. aureus. As shown in Figure 2(d), in mock-infected cells, blocking de novo biosynthesis resulted in a rapid decrease in the cellular levels of Mcl-1. By contrast, in cells infected with S. aureus, the level of Mcl-1 was significantly higher (Figure 2(d)). Cumulatively, these results clearly showed the dual nature of the effects of $S$. aureus on Mcl-1, which involved increased Mcl-1 protein synthesis as well as increased protein stability.

3.3. The Mcl-1 Expression Correlates with Prevalence and Severity of S. aureus-Induced Arthritis. S. aureus is the causative agent in about $60 \%$ of nongonococcal bacterial arthritis cases, a disease characterized among others by robust influx of macrophages and their sustain activation in joints $[15,16]$. Therefore, we determined Mcl-1 expression in inflamed joints in the previously established murine model of S. aureus arthritis [17]. To this end DBAl mice were injected i.v. with $5 \times 10^{7} \mathrm{CFU}$, a dose causing a low mortality rate (see Supplementary Figure 1(a) in Supplementary Material available online at http://dx.doi.org/10.1155/2013/427021). At day 8 after injection all animals showed clear symptoms of arthritis (Supplementary Figure 1(b)). Bacteriological examination of joints, spleen, and kidneys revealed the abundant load of S. aureus in 100\% of mice (Supplementary Figure $1(\mathrm{c})$ ). This finding correlates with inflammatory response manifested by IL-6 secretion (Supplementary Figure 1(d)) and splenomegaly (data not shown). Further investigation of the relationship between both clinical and bacteriological signs of arthritis and Mcl-1 expression in joints revealed the significant association (Figures 3(a) and 3(b)). We found Mcl1 expression being significantly upregulated in S. aureuspositive joints (32.83 \pm 7.94 -fold above the control level) in comparison to noninfected tissues (4.29 \pm 0.82 -fold above the control level, $P<0.001$ ). Furthermore, we also observed positive association between the Mcl-1 expression level and bacterial load in joints. This indicates that $S$. aureus induced Mcl-1 expression also in vivo in the inflamed tissue.

3.4. Downregulation of Mcl-1 Interferes with S. aureus-Induced Cytoprotection. As we described previously S. aureus protects infected macrophages, both human and murine, against induced cell death [7]. Thus, to further determine whether the survival of infected macrophages in response to proapoptotic stimulants was dependent on Mcl-1 synthesis, RNA interference with siRNA was used to selectively silence MCL1 gene expression. Treatment of cells with an MCL1-specific siRNA, but not a nonspecific control siRNA, resulted in specific and efficient suppression of Mcl-1 protein levels at 24-72 h after-transfection (data not shown) without effect on macrophages viability. The infection of macrophages $24 \mathrm{~h}$ after-transfection has not influenced the low level of already silenced protein within $24-48 \mathrm{~h}$ after infection (Figure 4(a)). The increasing caspase-3 activity (Figure 4(b)) and a lactate dehydrogenase leaking from macrophages (Figure 4(c)) revealed that the knockdown of MCL1 expression 


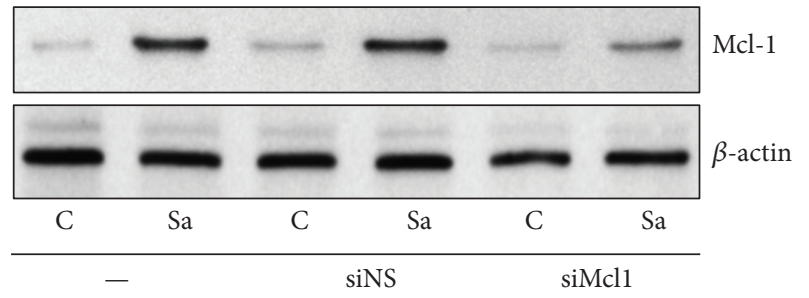

(a)

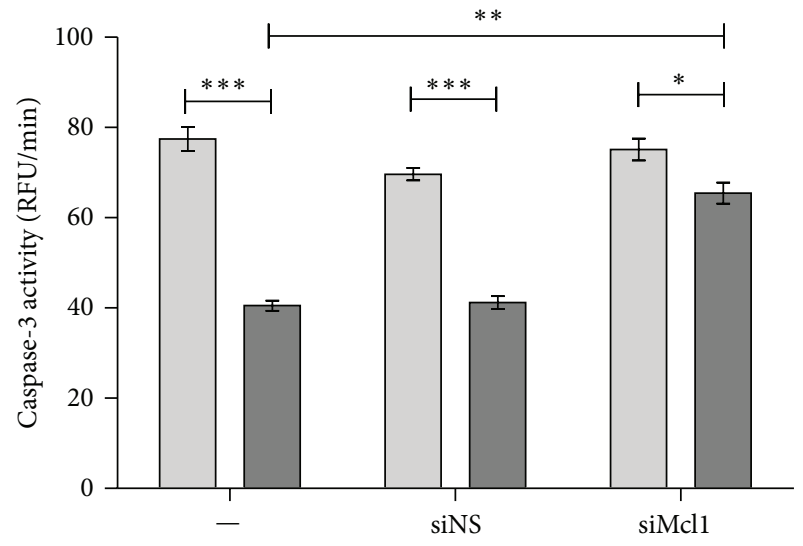

(b)

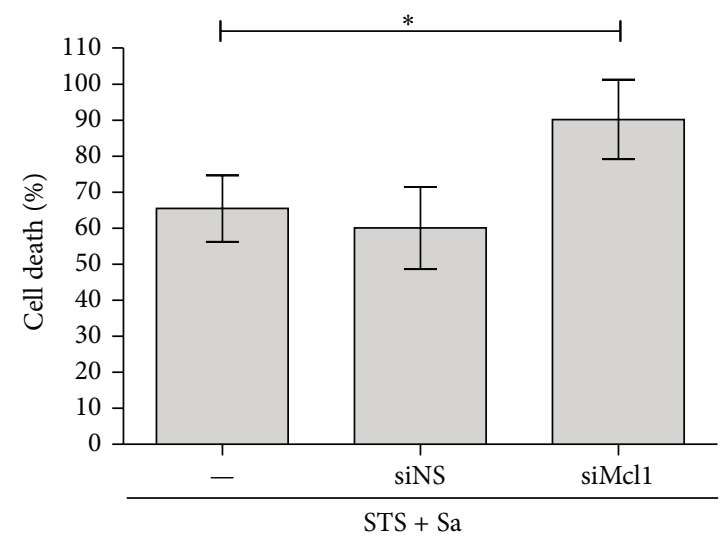

(c)

FIGURE 4: Effect of Mcl-1 expression on cytoprotection induced by S. aureus in hMDMs. (a) Human macrophages were treated with an MCL1 siRNA (siMCL1) or a nonspecific siRNA (siNS). At $24 \mathrm{~h}$ following transfection macrophages were infected with $S$. aureus at an MOI 1:50. After additional $24 \mathrm{~h}$ cells were collected and Mcl-1 expression was detected by immunoblot. Data are representative of three separate experiments using hMDMs derived from different donors. (b) The increase in caspase-3 activity (RFU/min) induced by STS in MCL1 knockdown macrophages infected with S. aureus. Twenty-four hours after treatment with siRNA, hMDMs were infected with S. aureus $(24 \mathrm{~h})$, followed by treatment with STS at a concentration of $1 \mu \mathrm{M}$ for $18 \mathrm{~h}$. The measurement of caspase- 3 activity (RFU/min) in cell lysates was performed using DEVD-AFC as a substrate. The figure is representative of three experiments, using hMDMs cultures obtained from different donors. Light bars-STS, dark bars-Sa + STS. Data represent means \pm SD. ${ }^{*} P<0.05 ;{ }^{* *} P<0.01$; ${ }^{* * *} P<0.001$. (c) Increased susceptibility to the cytotoxic effects of staurosporine (STS) in MCL1 knockdown macrophages infected with S. aureus. Twenty-four hours after treatment with siRNA, hMDMs were infected with $S$. aureus $(24 \mathrm{~h})$, followed by treatment with STS at a concentration of $1 \mu \mathrm{M}$ for $24 \mathrm{~h}$. Plasma membrane permeabilisation or cell lysis induced in the hMDMs was assessed by measuring LDH activity in the culture medium. LDH activity in the media of cells treated only with STS was arbitrarily set as $100 \%$. Results were calculated based on data ( \pm SD) from three separate experiments. ${ }^{*} \mathrm{P}<0.05$.

significantly attenuated the S. aureus-exerted cytoprotection of cells in a staurosporine-induced cell death model. Our data also indicates (Supplementary Figure 2) that silencing of $\mathrm{Mcl}$ 1 in $S$. aureus-infected macrophages partly ablates the cytoprotection against spontaneous cell death. This observation confirmed that Mcl-1 plays an important role in preventing apoptosis in $S$. aureus-infected human macrophages.

\subsection{S. aureus-Dependent Mcl-1 Expression Is Regulated by} IL-6. IL-6 upregulates Mcl-1 in human myeloma cells [18]. To determine whether IL-6 was also playing a role in $S$. aureus-induced Mcl-1 expression in hMDMs, macrophages were infected with $S$. aureus, what leads to IL-6 secretion within $24 \mathrm{~h}$ after infection (Supplement Figure 3). Both high mRNA and protein Mcl-1 expression observed after bacteria phagocytosis (Figures 5(a) and 5(b), resp.) was markedly reduced upon treatment of cells with IL- 6 receptor (R) neutralising antibodies. Together, these results demonstrated that S. aureus-induced Mcl-1 expression is partly mediated by IL-6.

3.6. The NFאB Pathway Is Involved in IL-6-Dependent Regulation of Mcl-1 Expression Induced by S. aureus. A variety of intracellular signalling pathways are activated by pathogens. 


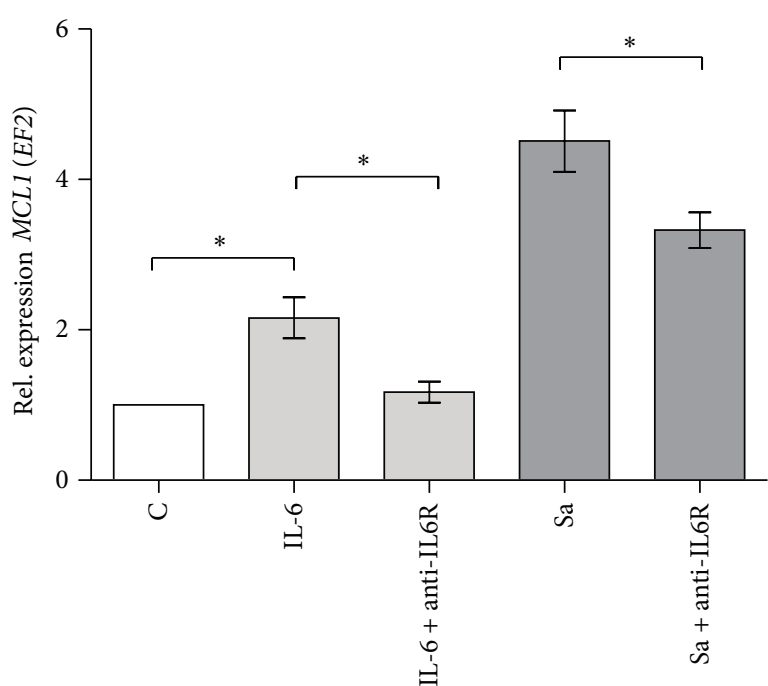

(a)

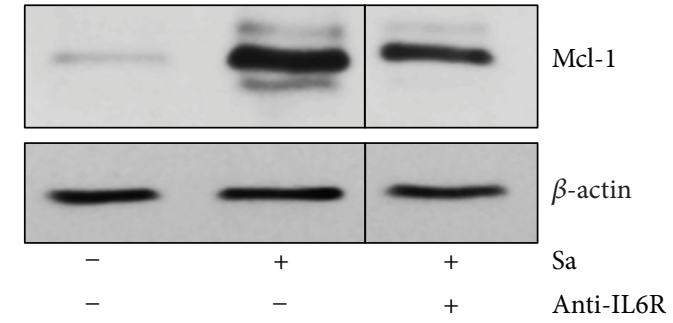

(b)

FIGURE 5: Mcl-1 expression induced by $S$. aureus is mediated by IL-6. (a) hMDMs were preincubated with anti-IL6 receptor antibodies $(1 \mu \mathrm{g} / \mathrm{mL})$ for $30 \mathrm{~min}$ and then infected with $S$. aureus at an MOI of 1:50 and/or stimulated with IL-6 (200 ng/mL). At $7 \mathrm{~h}$ p.i., RNA was extracted and relative MCL1 expression was measured by qRT-PCR. Diagram shows the mean values calculated from the results of at least three independent real-time reactions using hMDMs derived from different donors. Bars represent mean relative expression \pm SD. ${ }^{*} P<0.05$. (b) hMDMs were preincubated with anti-IL6 receptor $(1 \mu \mathrm{g} / \mathrm{mL})$ antibodies for $30 \mathrm{~min}$ and then infected with S. aureus Newman at an MOI of $1: 50$. The effect of $S$. aureus on Mcl-1 protein synthesis was measured $20 \mathrm{~h}$ after-infection by immunoblot. Shown is a representative immunoblot from three separate experiments performed on hMDMs derived from different donors.

Among them, activation of $\mathrm{NF} \kappa \mathrm{B}$ has been shown to be critical for cytoprotection of infected cells [19]. Moreover, $S$. aureus is a potent inducer of $\mathrm{NF} \kappa \mathrm{B}$ activity as was confirmed in infected macrophages by EMSA (Supplement Figure 4). To determine the effect of inhibition of the NF $\kappa$ B pathway on Mcl-1 expression in hMDMs, macrophages were infected with $S$. aureus followed by incubation for $6 \mathrm{~h}$ with a specific $\mathrm{NF} \kappa \mathrm{B}$-inhibitor, and then the levels of MCL1 were assessed in comparison to untreated infected cells. As seen in Figure 6(a), inhibition of the NFKB pathway abrogated the S. aureusinduced increase in MCL1 gene transcription. This effect was confirmed at the protein level as well (Figure 6(b)). These results strongly suggested that Mcl-1 expression in $S$. aureus-infected cells is dependent on NF $\kappa$ B. Since IL-6 transcription is upregulated in an $\mathrm{NF} \kappa \mathrm{B}$-dependent manner [20], we investigated the possibility that $\mathrm{NF} \kappa \mathrm{B}$ stimulated MCL1 expression indirectly, via IL-6. S. aureus-induced production of IL-6 in infected macrophages was abrogated by treatment with Bay 11-7095, the NF $\mathcal{B}$ B-specific cellpermeable inhibitor, which indicated that IL- 6 production was absolutely dependent on NFKB (Figure 6(c)). Taken together, these findings indicate that IL-6-mediated Mcl-1 expression in infected macrophages is regulated through the $\mathrm{NF} \kappa \mathrm{B}$ pathway.

Since we proved that the $S$. aureus mediated Mcl-1 induction in both human and murine model, therefore, in all further experiments we routinely use the hMDMs and/or RAW 264.7 cell line.
3.7. NFאB and IL-6 Are Required for S. aureus-Induced Inhibition of Macrophage Apoptosis. Based on the fact that S. aureus delayed apoptosis through Mcl-1 upregulation in infected macrophages we investigated whether NF $\kappa \mathrm{B}$-dependent pathways and/or IL-6 were necessary for $S$. aureus-induced inhibition of apoptosis. In this experiment we used both hMDMs and murine macrophage RAW 264.7 cell line, the latter to verify the results of Mcl-1 induction in mice joints by $S$. aureus infection. Preincubation of macrophages with an $\mathrm{NF} \kappa \mathrm{B}$ inhibitor (Bay 11-7095) reversed antiapoptotic effect (measured by caspase- 3 activation) induced by $S$. aureus in staurosporine-treated cells (Figure 7(a)). The viability of hMDMs was also assessed after blocking IL-6 signalling. Pretreatment of human macrophages with IL-6R neutralising antibodies partly abolished $S$. aureus-induced protection against cell death exerted by staurosporine, but had no effect on cytoprotection against cycloheximide- (CHX-) mediated cell death (Figure 7(b)). To determine whether IL-6 acted in an autocrine manner to prevent cell death induced by staurosporine, conditioned media from $S$. aureus-infected macrophages containing abundant IL-6 (Supplement Figure 3) was added to noninfected macrophages, followed by treatment of the cells with staurosporine. To confirm the role of secreted upon S. aureus infection IL-6 on suppression of macrophages apoptosis we blocked the action of IL- 6 using anti-IL6 receptor $(1 \mu \mathrm{g} / \mathrm{mL})$ antibodies. Measurement of caspase- 3 activity revealed a significant effect, albeit one that was weaker than that induced by $S$. aureus infection, of 


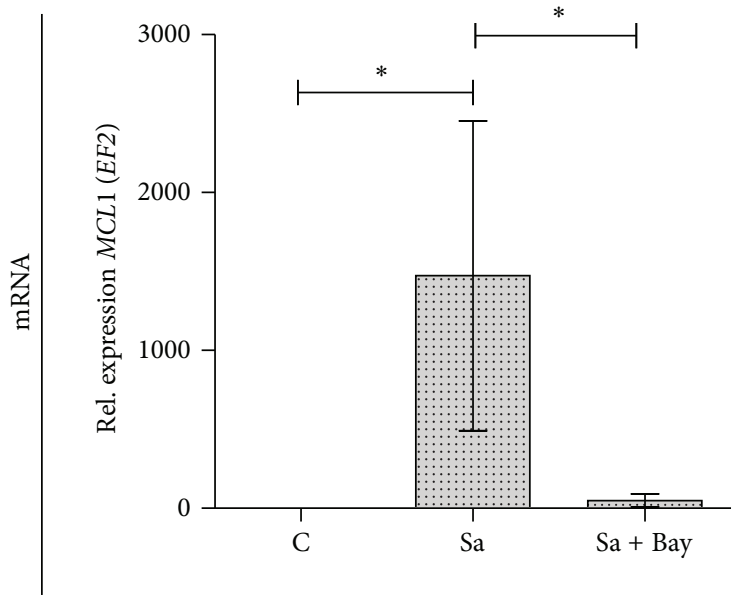

(a)

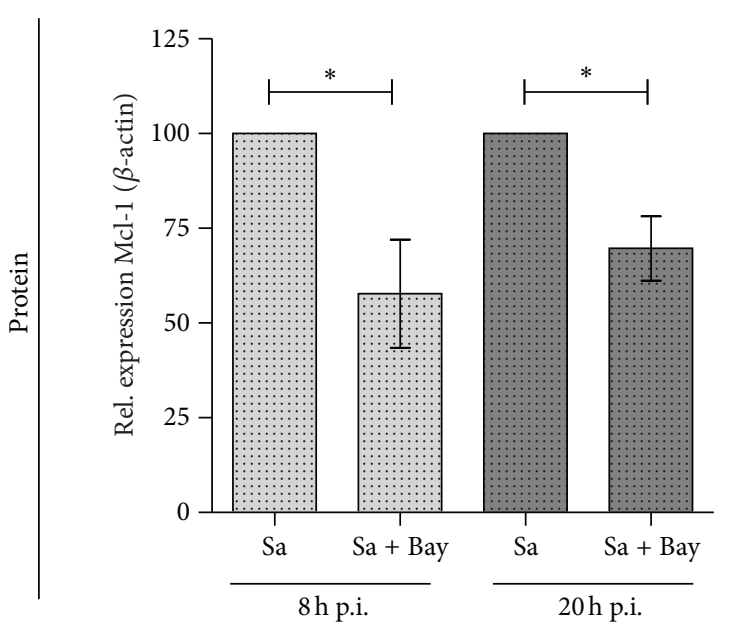

(b)

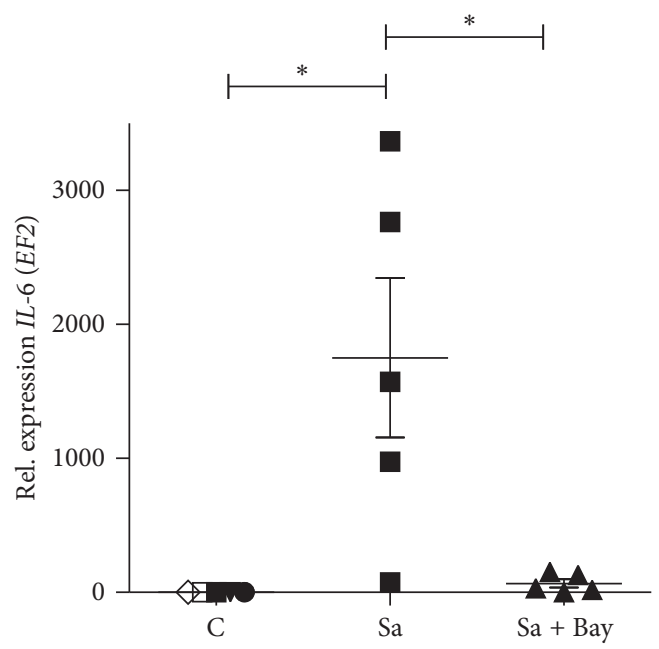

(c)

FIGURE 6: NFאB is required for Mcl-1 expression induced by S. aureus. (a, b) hMDMs were pretreated for 30 min with Bay 11-7095 (40 $\mu$ M) followed by $S$. aureus infection at an MOI of 50. After the indicated times, RNA and protein were extracted and Mcl-1 expression levels were determined by qRT-PCR and immunoblot (a and b, resp.). Data represent the means \pm SD from three separate experiments. ${ }^{*} P<0.05$. (c) The effect of NF $\kappa$ B inhibition on IL-6 expression was measured by qRT-PCR. Shown are the mean values calculated from the results of five independent real-time reactions using hMDMs derived from different donors. Bars represent mean relative expression \pm SD; ${ }^{*} P<0.05$.

the conditioned medium on cytoprotection, which can be partly reversed by IL-6 signalling inhibition (Figure 7(c)). Cumulatively, these data demonstrate that the induction of IL-6 production in macrophages upon $S$. aureus infection is an important factor in the activation of downstream events that lead to suppression of the intrinsic apoptotic pathway through de novo synthesis Mcl-1.

\section{Discussion}

Results from recent in vitro studies have demonstrated that macrophages infected with $S$. aureus are resistant to apoptosis (both induced and spontaneous), and this apparent cytoprotective effect is a consequence of the significant upregulation of antiapoptotic genes, especially those involved in the mitochondrial pathway, such as MCL1 [7]. Here, we investigated this phenomenon in more detail and showed for the first time that $S$. aureus-induced resistance to cell death is highly dependent on Mcl-1 expression since specific silencing of MCL1 abrogated the effect. In this respect, S. aureus clearly resembles $M$. tuberculosis or respiratory syncytial virus (RSV), well-known obligatory intracellular pathogens that employ a similar strategy [21, 22].

Mcl-1 is a short-lived cytoplasmic protein (half-life of approximately $3 \mathrm{~h}$ ) destined for prompt degradation by the proteasome $[23,24]$. This fast proteolytic removal of Mcl1 was markedly slowed in $S$. aureus-infected macrophages. The level of Mcl-1 rapidly increased within $2 \mathrm{~h}$ after bacterial infection, reached a maximum at $6 \mathrm{~h}$, and then remained elevated for up to $24 \mathrm{~h}$. In addition to enhanced MCL1 gene expression [7], this increase in Mcl-1 levels was due in large part to increased Mcl-1 stability. In contrast to 


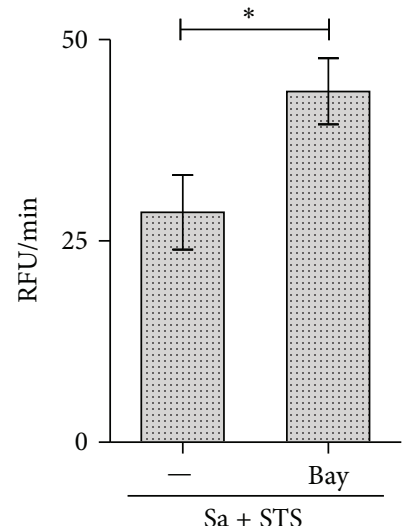

(a)

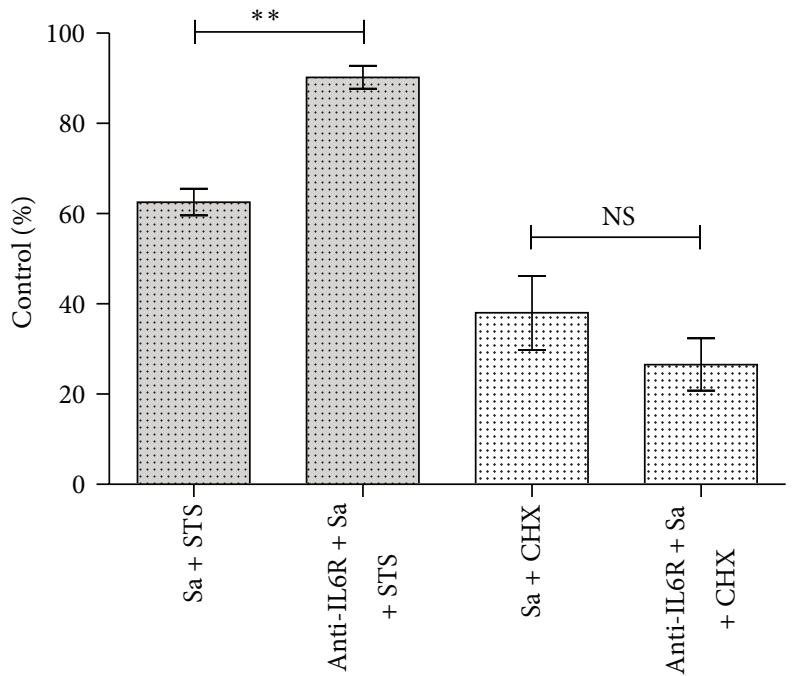

(b)

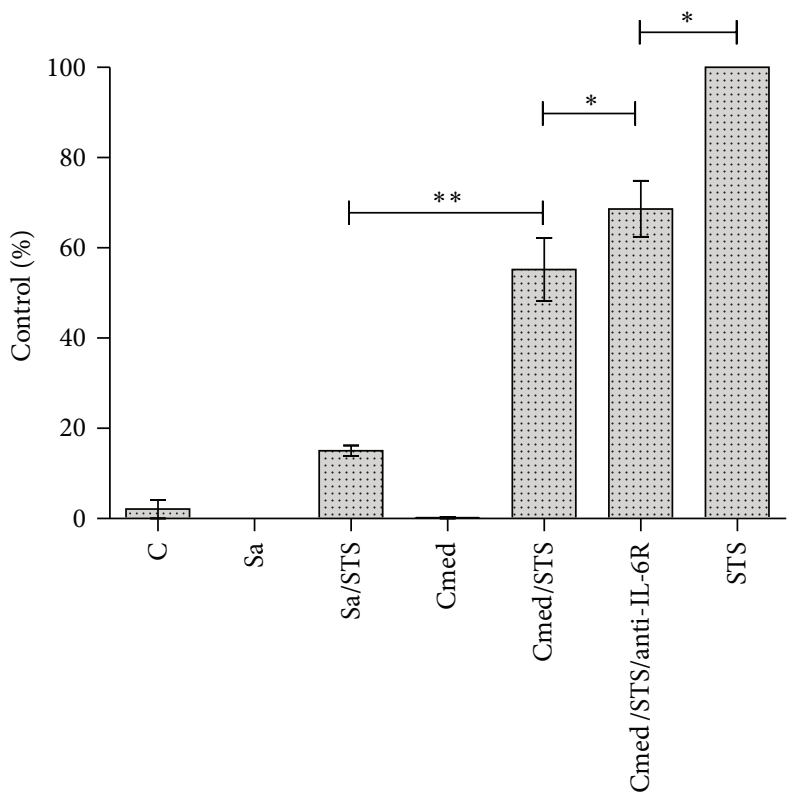

(c)

FIGURE 7: The role of NFאB and IL-6 in cytoprotection induced by S. aureus. (a) Inhibition of S. aureus-induced cytoprotection upon treatment with an NF $\kappa$ B inhibitor was assessed by measuring caspase-3 activation. RAW 264.7 macrophages were pretreated for 30 min with Bay 11-7095 $(4 \mu \mathrm{M})$ followed by bacterial infection at an MOI of 5 for $2 \mathrm{~h}$. STS was added for an additional $3 \mathrm{~h}$, and then caspase- 3 activity was measured in cell lysates (as described in Section 2). Data represent mean $\pm \mathrm{SD}$ caspase- 3 activity (RFU/min) from three separate experiments. ${ }^{*} P<0.05$. $(b, c)$ The influence of IL-6 on STS- $(1 \mu \mathrm{M})$ or CHX- $(10 \mu \mathrm{M})$ induced cytotoxicity in S. aureus-infected macrophages. (b) hMDMs were preincubated with anti-IL6 receptor antibodies $(1 \mu \mathrm{g} / \mathrm{mL})$ for $1 \mathrm{~h}$ followed by S. aureus infection at an MOI of $1: 50$ for 2 . STS or CHX was added for $6 \mathrm{~h}$, and then permeabilisation of the plasma membrane or cell lysis was determined by measuring LDH activity in conditioned media. Cell death after treatment with STS or CHX alone was set as $100 \%$. Diagram shows the mean values calculated from the results of three independent experiments using hMDMs derived from different donors. Bars represent mean relative expression \pm SD; ${ }^{* *} P<0.01$; NS: not significant. (c) RAW 264.7 cells were infected with S. aureus (MOI 1:5) or stimulated with conditioned medium collected from infected RAW 264.7 cells $5 \mathrm{~h}$ p.i. alone (cmed) or with anti-IL6 receptor $(1 \mu \mathrm{g} / \mathrm{mL})$ antibodies (cmed + anty-IL6R). At $2 \mathrm{~h}$ after stimulation, macrophages were treated with STS for another $4 \mathrm{~h}$ and then caspase- 3 activity was measured. Caspase- 3 activation induced by STS alone was set as $100 \%$. Shown are mean values calculated from the results of three independent experiments. Bars represent mean relative expression \pm $\mathrm{SD} ;{ }^{*} \mathrm{P}<0.05 ;{ }^{* *} \mathrm{P}<0.01$. 
control cells, the relative levels of Mcl-1 in infected cells were only slightly decreased by inhibition of protein translation. This is consistent with the resistance of $S$. aureus infected macrophages to cell death experimentally induced by cycloheximide. Thus, apoptosis inhibition in macrophages following $S$. aureus infection involves both enhancement of MCL1 transcription and the prolonged life-time of $\mathrm{Mcl}$ 1 in infected cells. This underscores the essential role of antiapoptotic Mcl-1 in S. aureus-induced cytoprotection in macrophages and argues that hijacking of Mcl-1 function is essential for survival of infected cells thus facilitating survival of intracellular invaders.

The confirmation of Mcl-1 role in staphylococcal infection was obtained studying $S$. aureus-induced septic arthritis. Our data clearly shows enhanced Mcl-1 expression in infected joints. This suggests that also in vivo S. aureus yields cytoprotection to infected cells establishing a safe haven impervious to attack by antibacterial forces of the immune system. Taking into account that the majority of synovial cells in the cartilage-synovium junction that participate in the destructive process are macrophages, the prolonged life-spam of infected phagocytes may be directly linked to the severity of septic arthritis lesions. Our hypothesis is corroborated by both the level of bacterial infection/spreading and the Mcl-1 expression in peritoneal macrophages isolated from $S$. aureus-infected mice, which are higher in comparison to macrophages from infected animals additionally exposed to $\mathrm{NF} \kappa \mathrm{B}$ or IL- 6 signalling inhibitors (data not shown).

IL-6 plays an important role in pathogenesis of septic arthritis promoting synovitis, manifested by stimulation of chemokines and adhesion molecules and infiltration of inflammatory cells, such as macrophages and lymphocytes. IL- 6 has been also shown to be essential for Mcl-1 expression thus promoting accumulation of macrophages [25]. Therefore, $S$. aureus-induced IL-6 secretion could be responsible for Mcl-1 upregulation in infected macrophages. In keeping with this, Mcl-1 induction was partly attenuated by specifically blocking the IL-6R, which suggests an autocrine role of IL- 6 in the $S$. aureus-induced cytoprotection of infected macrophages through increased expression of Mcl-1. This effect is regulated by the $\mathrm{NF} \kappa \mathrm{B}$ pathway as it is apparent from the observation that $\mathrm{Mcl}-1$ expression was decreased upon inhibition of $\mathrm{NF} \kappa \mathrm{B}$. However, it should be underlined that, since Mcl-1 can be induced by several different survival and differentiation signals, both on transcriptional and posttranscriptional levels, the involvement of NF $\kappa \mathrm{B}$ and IL6 pathways in this process is a part of the very complex regulation network.

Interactions between hosts and pathogens vary depending on the strategies employed by the pathogens to deter host immunity. Therefore, defining the defence mechanisms that are selective for a particular pathogen or, conversely, the precise virulence strategy of the pathogen is a crucial step in predicting the outcome of infection. Described here and in a previous report [7] sustained $\mathrm{Mcl}-1$ expression and cytoprotection of macrophages by $S$. aureus following infection appears to be specific for this bacterium, since engulfment of Gram-negative bacteria or latex beads yielded negligible effects. Such highly specific activation of Mcl-1 expression could be beneficial for the host or advantageous for S. aureus. Pathogen persistence or replication in a protected intracellular environment and dissemination before infected cells are removed by Fas-mediated apoptosis argue strongly for the latter option. A similar strategy is employed by $M$. tuberculosis, an obligatory intracellular pathogen, which employs a strategy whereby intracellular replication is prolonged by Mcl-1 upregulation and inhibition of apoptosis, hence promoting chronic persistence [22]. The opposite mode of action has been documented for Streptococcus pneumoniae infection, where initial enhancement of macrophage viability allows professional phagocytes to eradicate the infection [26].

Therefore, based on presented data we propose the scenario in which intracellular $S$. aureus makes macrophages resistant to apoptosis thus using these mobile cells as the Trojan horse to disseminate. The follow-up study aimed to unambiguously verify this attractive hypothesis is in progress in our laboratory.

\section{Conclusions}

To sum up, our work describes the mechanism of Mcl-1 induction and its pivotal role in S. aureus-mediated cytoprotection of infected macrophages. Moreover, the upregulation of Mcl-1 in vivo indicates that observed phenomenon plays a role during staphylococcal infection.

\section{Acknowledgments}

This study was supported by JK Grant no. N N301 050439 from Polish Ministry of Science and Higher Education. The Faculty of Biochemistry, Biophysics and Biotechnology of the Jagiellonian University is a beneficiary of structural funds from the European Union (Grant no. POIG.02.01.00-12064/08: "Molecular biotechnology for health"). The funders had no role in study design, data collection and analysis, decision to publish, or preparation of the paper.

\section{References}

[1] F. D. Lowy, "Medical progress: Staphylococcus aureus infections," New England Journal of Medicine, vol. 339, no. 8, pp. 520-532, 1998.

[2] J. M. Voyich, K. R. Braughton, D. E. Sturdevant et al., "Insights into mechanisms used by Staphylococcus aureus to avoid destruction by human neutrophils," Journal of Immunology, vol. 175, no. 6, pp. 3907-3919, 2005.

[3] M. Kubica, K. Guzik, J. Koziel et al., "A potential new pathway for Staphylococcus aureus dissemination: the silent survival of $S$. aureus phagocytosed by human monocyte-derived macrophages," PLoS ONE, vol. 3, no. 1, article e1409, 2008.

[4] D. A. Drevets, "Dissemination of Listeria monocytogenes by infected phagocytes," Infection and Immunity, vol. 67, no. 7, pp. 3512-3517, 1999.

[5] O. F. Join-Lambert, S. Ezine, A. Le Monnier et al., "Listeria monocytogenes-infected bone marrow myeloid cells promote bacterial invasion of the central nervous system," Cellular Microbiology, vol. 7, no. 2, pp. 167-180, 2005. 
[6] D. G. Russell, "Who puts the tubercle in tuberculosis?" Nature Reviews Microbiology, vol. 5, no. 1, pp. 39-47, 2007.

[7] J. Koziel, A. Maciag-Gudowska, T. Mikolajczyk et al., "Phagocytosis of Staphylococcus aureus by macrophages exerts cytoprotective effects manifested by the upregulation of antiapoptotic factors," PLoS ONE, vol. 4, no. 4, article e5210, 2009.

[8] K. M. Kozopas, T. Yang, H. L. Buchan, P. Zhou, and R. W. Craig, "MCL1, a gene expressed in programmed myeloid cell differentiation, has sequence similarity to BCL2," Proceedings of the National Academy of Sciences of the United States of America, vol. 90, no. 8, pp. 3516-3520, 1993.

[9] C. L. Day, L. Chen, S. J. Richardson, P. J. Harrison, D. C. S. Huang, and M. G. Hinds, "Solution structure of prosurvival Mcl-1 and characterization of its binding by proapoptotic $\mathrm{BH} 3-$ only ligands," Journal of Biological Chemistry, vol. 280, no. 6, pp. 4738-4744, 2005.

[10] R. W. Craig, "MCL1 provides a window on the role of the BCL2 family in cell proliferation, differentiation and tumorigenesis," Leukemia, vol. 16, no. 4, pp. 444-454, 2002.

[11] K. J. Livak and T. D. Schmittgen, "Analysis of relative gene expression data using real-time quantitative PCR and the 2-

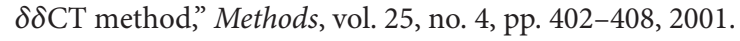

[12] L. Skalniak, D. Mizgalska, A. Zarebski, P. Wyrzykowska, A. Koj, and J. Jura, "Regulatory feedback loop between NF- $\kappa$ B and MCP-1-induced protein 1 RNase," The FEBS Journal, vol. 276, no. 20, pp. 5892-5905, 2009.

[13] P. Zhou, L. Qian, C. K. Bieszczad et al., "Mcl-1 in transgenic mice promotes survival in a spectrum of hematopoietic cell types and immortalization in the myeloid lineage," Blood, vol. 92, no. 9, pp. 3226-3239, 1998.

[14] P. Zhou, L. Qian, K. M. Kozopas, and R. W. Craig, "Mcl-1, a Bcl2 family member, delays the death of hematopoietic cells under a variety of apoptosis-inducing conditions," Blood, vol. 89, no. 2, pp. 630-643, 1997.

[15] D. L. Goldenberg, P. L. Chisholm, and P. A. Rice, "Experimental models of bacterial arthritis: a microbiological and histopathologic characterization of the arthritis after the intraarticular injections of Neisseria gonorrhoeae, Staphylococcus aureus, group A streptococci, and Escherichia coli," Journal of Rheumatology, vol. 10, no. 1, pp. 5-11, 1983.

[16] D. L. Goldenberg, "Infectious arthritis complicating rheumatoid arthritis and other chronic rheumatic disorders," Arthritis and Rheumatism, vol. 32, no. 4, pp. 496-502, 1989.

[17] T. Bremell, S. Lange, A. Yacoub, C. Ryden, and A. Tarkowski, "Experimental Staphylococcus aureus arthritis in mice," Infection and Immunity, vol. 59, no. 8, pp. 2615-2623, 1991.

[18] D. Puthier, R. Bataille, and M. Amiot, "IL-6 up-regulates mcl-1 in human myeloma cells through JAK / STAT rather than ras / MAP kinase pathway," European Journal of Immunology, vol. 29, pp. 3945-3950, 1999.

[19] G. Bonizzi and M. Karin, "The two NF- $\kappa$ B activation pathways and their role in innate and adaptive immunity," Trends in Immunology, vol. 25, no. 6, pp. 280-288, 2004.

[20] W. Vanden Berghe, L. Vermeulen, G. De Wilde, K. De Bosscher, E. Boone, and G. Haegeman, "Signal transduction by tumor necrosis factor and gene regulation of the inflammatory cytokine interleukin-6," Biochemical Pharmacology, vol. 60, no. 8, pp. 1185-1195, 2000.

[21] C. A. Lindemans, P. J. Coffer, I. M. M. Schellens, P. M. A. De Graaff, J. L. L. Kimpen, and L. Koenderman, "Respiratory syncytial virus inhibits granulocyte apoptosis through a phosphatidylinositol 3-kinase and NF- $\kappa$ B-dependent mechanism," Journal of Immunology, vol. 176, no. 9, pp. 5529-5537, 2006.

[22] L. M. Sly, S. M. Hingley-Wilson, N. E. Reiner, and W. R. McMaster, "Survival of Mycobacterium tuberculosis in host macrophages involves resistance to apoptosis dependent upon induction of antiapoptotic Bcl-2 family member Mcl-1," Journal of Immunology, vol. 170, no. 1, pp. 430-437, 2003.

[23] D. A. Moulding, C. Akgul, M. Derouet, M. R. H. White, and S. W. Edwards, "BCL-2 family expression in human neutrophils during delayed and accelerated apoptosis," Journal of Leukocyte Biology, vol. 70, no. 5, pp. 783-792, 2001.

[24] T. Yang, K. M. Kozopas, and R. W. Craig, "The intracellular distribution and pattern of expression of Mcl-1 overlap with, but are not identical to, those of Bcl-2," Journal of Cell Biology, vol. 128, no. 6, pp. 1173-1184, 1995.

[25] M. Jourdan, J. De Vos, N. Mechti, and B. Klein, "Regulation of Bcl-2-family proteins in myeloma cells by three myeloma survival factors: Interleukin-6, interferon-alpha and insulin-like growth factor 1," Cell Death and Differentiation, vol. 7, no. 12, pp. 1244-1252, 2000.

[26] H. M. Marriott, C. D. Bingle, R. C. Read et al., "Dynamic changes in Mcl-1 expression regulate macrophage viability or commitment to apoptosis during bacterial clearance," Journal of Clinical Investigation, vol. 115, no. 2, pp. 359-368, 2005. 


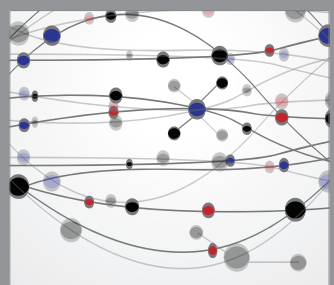

The Scientific World Journal
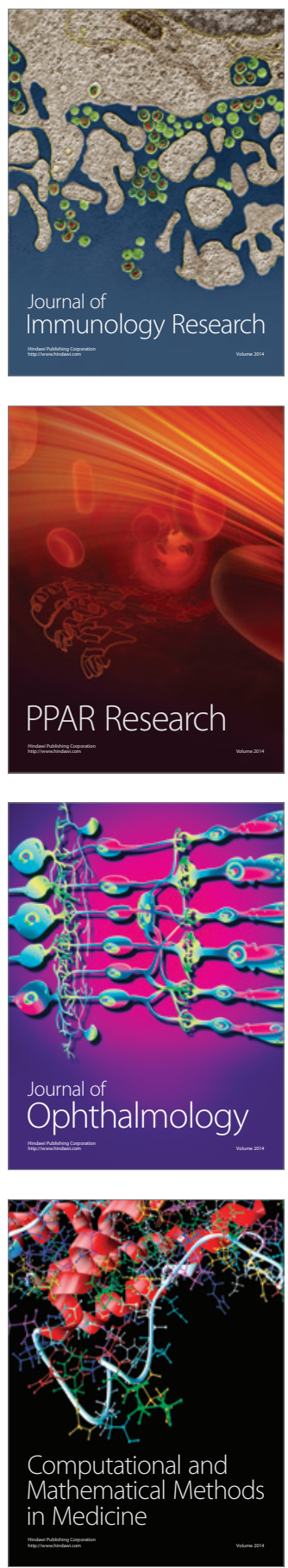

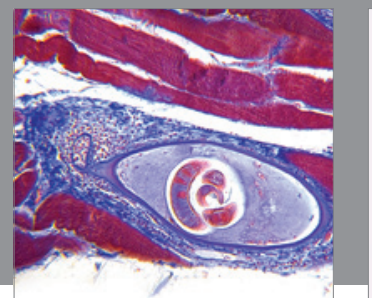

Gastroenterology

Research and Practice
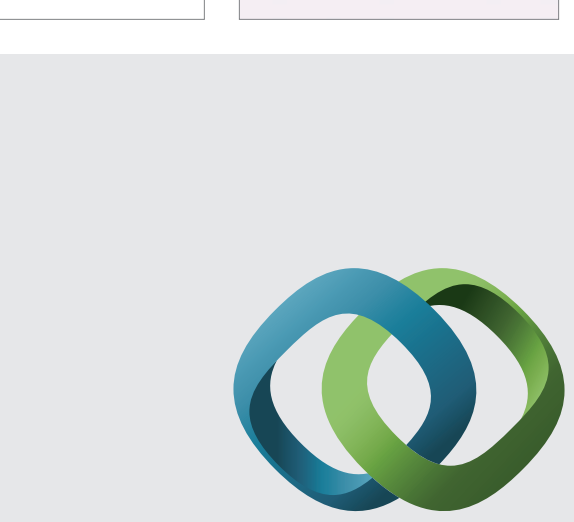

\section{Hindawi}

Submit your manuscripts at

http://www.hindawi.com
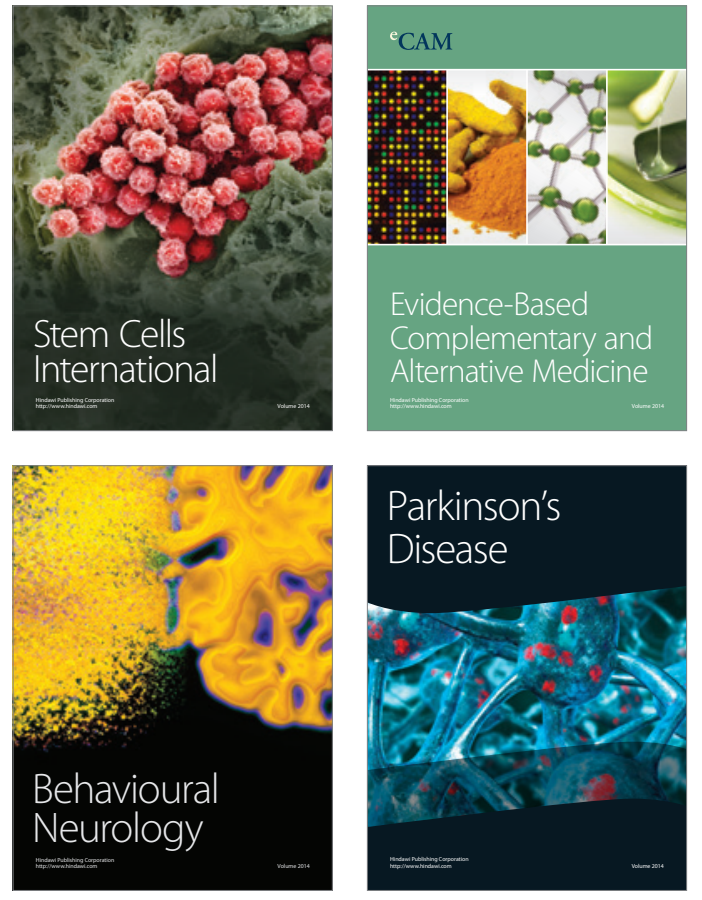
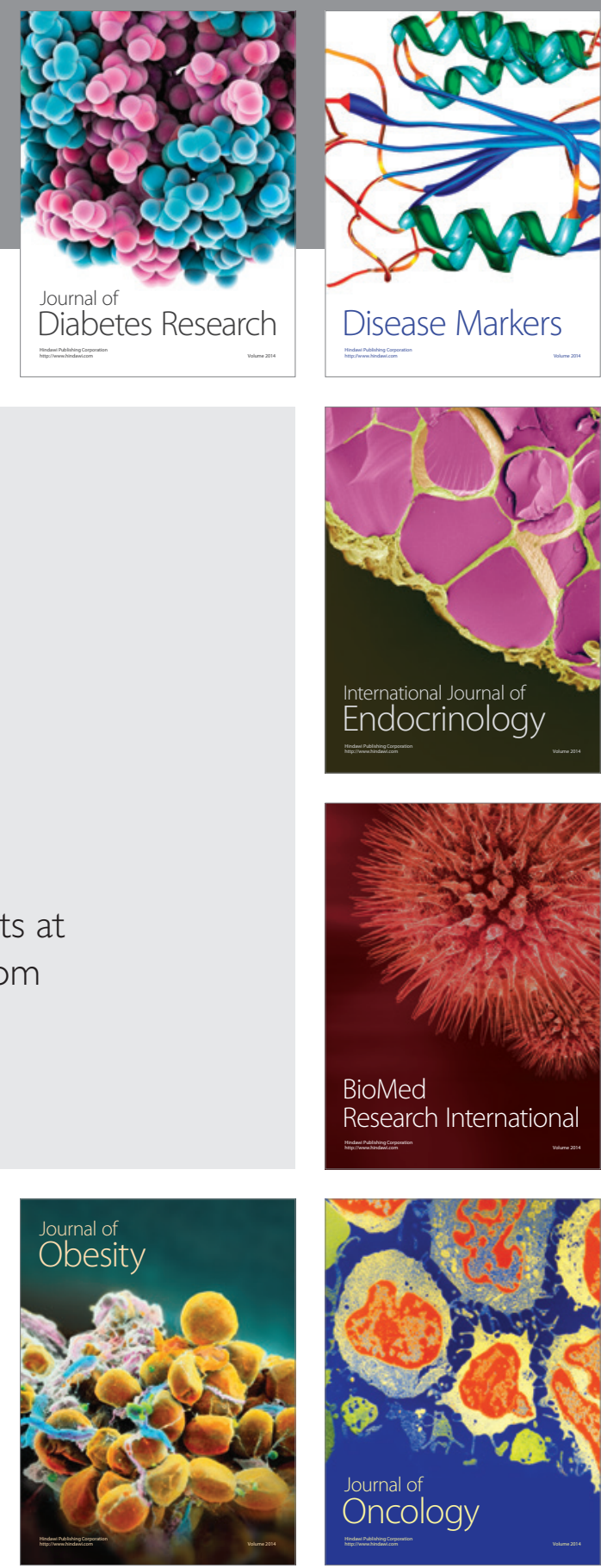

Disease Markers
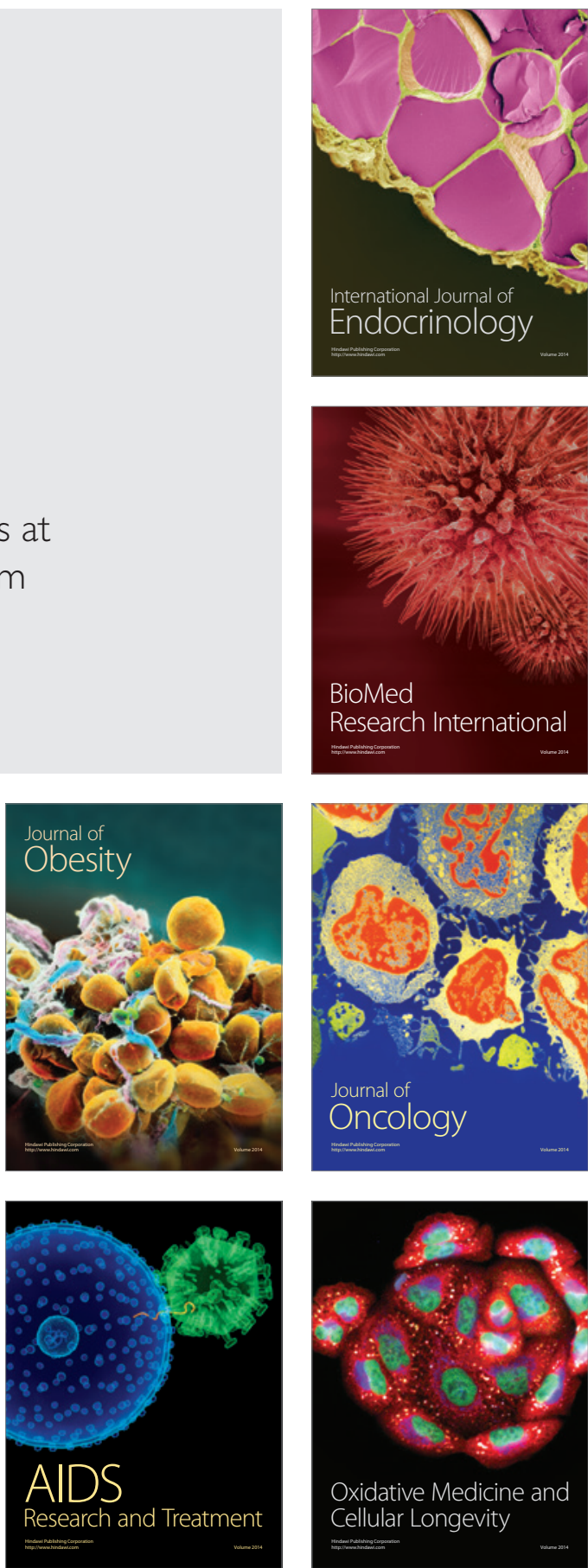